\section{El desarrollo del niño hasta los 12 meses. Orientaciones al pediatra para su vigilancia con la familia}

\section{RESUMEN}

El pediatra tiene un papel de primera importancia en la vigilancia y promoción del desarrollo de los niños; los padres estiman que es el profesional que puede orientarlos para saber si su desarrollo es normal y sobre la forma de proveer cuidados para favorecerlo. Para atender estas demandas el pediatra debe utilizar distintas herramientas que le permitan comprender la forma en que se va organizando el desarrollo del niño, pero a la vez la forma en que los cuidados, organización del ambiente y condiciones de riesgo y alarma pueden impactar en su evolución. No basta con aplicar pruebas de cribado, deben observarse además los procesos de crianza y la forma en qué aspectos del entorno pueden favorecer o limitar el desarrollo, acompañándose de recomendaciones claras que lo promuevan.

El objetivo primario de este artículo es Ilamar la atención del pediatra sobre la necesidad de asesorar a los padres sobre su capacidad para vigilar y favorecer el desarrollo normal y el cuidado de sus hijos en las actividades de la vida cotidiana. Señalamos aspectos del desarrollo susceptibles de ser observados regularmente y sobre los que se puede incidir mediante recomendaciones que modulen la relación con el niño. Exponemos una visión clínica del desarrollo infantil que permita, de manera sencilla, resolver las necesidades de los padres sobre cómo supervisar y conducir el desarrollo de sus hijos. Les proponemos complementar su evaluación con indicaciones y sugerencias para que aprendan a observar a sus hijos, siguiendo determinadas secuencias que de no cumplirse indican al pediatra una condición de riesgo y la necesidad de aplicar una prueba de tamizado completa u otra de mayor especialización en la que se tenga experiencia.

Palabras clave: desarrollo, vigilancia, primer año.

\section{The development of the child up to 12 months. Orientations to the pediatrician for its surveillance with the family}

\section{ABSTRACT}

The pediatrician has a major role in surveillance and promotion of child development. Parents consider him the professional who may provide guidance about normal development and of how to provide care to foster it. To meet these demands, the pediatrician should resort to the use of different tools that allow him to understand how child development organizes and how breeding care, environment organization and risk and alarming situation may impact on its evolution. Applying

\author{
Carmen Sánchez-Pérez \\ Rolando Rivera-González \\ Alicia Correa-Ramírez \\ Miriam Figueroa \\ Antonio Sierra-Cedillo \\ Silvia Clementina Izazola
}

Laboratorio de Seguimiento del Neurodesarrollo, Instituto Nacional de Pediatría, México.
Recibido: 2 de marzo del 2015

Aceptado: 5 de octubre del 2015

Correspondencia: Dra. Carmen Sánchez Pérez Laboratorio de Seguimiento del Neurodesarrollo Instituto Nacional de Pediatría carmens@att.net.mx

Este artículo debe citarse como Sánchez-Pérez C, Rivera-González R, Correa-Ramírez A, Figueroa M, Sierra-Cedillo A, Izazola SC. El desarrollo del niño hasta los 12 meses. Orientaciones al pediatra para su vigilancia con la familia. Acta Pediatr Mex 2015;36:480-496. 
screening tests is not enough; evaluation of breeding practices and of how environmental features may favor or limit development should be implemented and complemented with clear recommendations aimed to promote it. The primary aim of this article is to call the pediatrician's attention on the need to counsel parents about their ability to survey and promote normal development through the care of their children in everyday life. We point out developmental aspects that can be regularly observed on which they may impact through recommendations that modulate the relation with the child. We expose a clinical vision of infant development that allows him to easily meet parents' needs concerning their children's development. We propose to supplement their assessment with directions and suggestions that may be given them so they can learn to observe their children following certain sequences that, when not accomplished, should alert the pediatrician about of a risk condition and the need of applying a complete screening or a more specialized test in which he is experienced.

Key words: Development, surveillance, first year, early childhood.

\section{INTRODUCCIÓN}

La etapa de lactante es una de las más relevantes para el futuro de los niños y la familia es la responsable directa de proporcionar a los hijos un cuidado orientado hacia la promoción de su desarrollo. En el transcurso de su crecimiento el niño responde a las demandas del ambiente y busca satisfacer sus necesidades, ampliando su capacidad adaptativa con recursos cada vez más complejos, estables y variados. Al participar activamente, sus funciones se transforman y organizan jerárquica y progresivamente de forma que es posible reconocer con el paso del tiempo diferentes secuencias. ${ }^{1}$ Estas secuencias o cambios evolutivos de determinadas funciones tienen una programación genética, pero están moduladas por la riqueza y calidad de formas de interacción o participación con su entorno, lo cual a su vez puede verse favorecido o afectado por factores biológicos de un cuerpo en desarrollo o por circunstancias psicosociales. ${ }^{2}$

Reconocer a los niños como seres activos que se involucran en el mundo ${ }^{3}$ obliga a aproximarnos a su desarrollo en el contexto de su vida cotidiana. La vida cotidiana se desenvuelve en el entorno familiar cuyo conjunto de prácticas de crianza favorece construir, modificar y ampliar las expresiones conductuales, demandas y requerimientos del niño. Las prácticas adecuadas de crianza son necesarias para propiciar la organización y la regulación de las funciones y competencias del individuo, que le permitirán su adaptación a las presiones y requerimientos del medio, especialmente en las primeras etapas del desarrollo. ${ }^{4}$

Los pediatras vigilan el desarrollo a través de la identificación de elementos de salud o riesgo a edades específicas, mediante pruebas de cribado con base en datos confiables. Las pruebas son útiles siempre y cuando estén basadas en parámetros poblacionales similares a los del niño que se evalúa.

Los padres generalmente se preocupan por saber si sus hijos ven y escuchan adecuadamente y si están físicamente íntegros. Solicitan información sobre los cuidados en casa, especialmente sobre la alimentación y las excretas, pero pocas veces 
sobre hábitos de sueño, formas de traslado o sobre cómo el niño juega e interactúa con el medio.

Durante las visitas mensuales, indicadas normativamente para el seguimiento de los lactantes menores, los padres comienzan a referir los avances en el desarrollo del hijo, especialmente cuando lo comparan con otros niños, a edades en las que algunas conductas Ilaman su atención. Sin embargo, para asesorar a los padres en el desarrollo integral del niño, el pediatra presta poca atención a algunas secuencias del desarrollo que se consideran adquisiciones tardías (a pesar de iniciarse en las etapas más tempranas) y menos aún, a la organización de la vida diaria y cotidiana del cuidador y del niño para favorecer las interacciones: cuidador-niño, niño-ambiente. Es aquí donde consideramos que la orientación a la familia sobre cómo observar y guiar el desarrollo del niño debe ser el punto de interés principal siguiendo los principios generales del desarrollo en contexto con una visión muy práctica y operativa. ${ }^{4,5}$

Si el pediatra aprende a reconocer las secuencias del desarrollo desde sus primeras etapas, sin limitarse a evaluar el desarrollo con base en la adquisición de conductas en edades establecidas, detectará tempranamente signos de alarma que representan obstáculos para la adquisición de dichas conductas y podrá orientar a los padres sobre los cuidados en casa para insistir sobre ellos.

Proponemos que el interés del pediatra se centre también en las adquisiciones del desarrollo y que las recomendaciones específicas para favorecerlo se encaminen a indagar y orientar a la familia, especialmente al cuidador principal, para promover sus competencias de observar y organizar las actividades diarias del niño en su contexto sociocultural. Al contrario de orientaciones que sin caracterizar detenidamente a cada niño recomiendan en todos ejercicios o masajes que proceden de técnicas terapéuticas o sugieren la inserción temprana a programas de estimulación cuando el niño presenta algunos desfases, o los padres le solicitan su opinión al respecto. Tampoco se trata de informar a los padres sobre el uso de juguetes sofisticados desde edades muy tempranas, sin mayor atención al juego y su correspondencia con el desarrollo alcanzado por el niño. Esta clase de recomendaciones contribuye a desvirtuar el entendimiento de los padres sobre las formas naturales de favorecer el desarrollo.

En la vida cotidiana las acciones de cuidado de la familia son reguladoras de las interacciones, promoviendo el desarrollo de un niño sano y con capacidades sociales, limitando retrasos o desviaciones.

Algunos principios generales del desarrollo que deben considerarse para una vigilancia adecuada se indican en los términos siguientes:

- El desarrollo es un proceso integral que comprende funcionamientos como la regulación interna, la estabilidad emocional y afectiva, el control de la postura, el movimiento, el juego, la información a través de la mirada, la escucha, la atención, el lenguaje, otras formas de comunicación no verbal, la inteligencia y la socialización. No debe reducirse su apreciación a una sola de estas áreas.

- Las secuencias de desarrollo parten de reflejos que se van integrando en conductas voluntarias cada vez más complejas. Reconocer las secuencias desde sus primeras fases permite detectar tempranamente signos de alarma (señales rojas) sobre los que se puede intervenir para evitar alteraciones futuras.

- Los cambios que se observan en los niños propician una mayor capacidad 
de adaptación a través de la edad. La velocidad en su adquisición y la calidad de las ejecuciones son referencia para apreciar la normalidad, aunque se presentan variaciones importantes entre los individuos estrechamente relacionados con las condiciones de su ambiente.

- La observación de las conductas a las edades indicadas en una prueba de tamizado no es criterio suficiente de normalidad, es importante la calidad de su producción.

El objetivo de este escrito es Ilamar la atención de los pediatras sobre la necesidad de asesorar a los padres sobre sus capacidades para vigilar y favorecer en sus hijos un desarrollo armónico. Se presenta una propuesta al pediatra para conducir la relación padre-niño, haciendo énfasis en algunos elementos del desarrollo infantil que no figuran en las escalas y procedimientos de cribado, dando las sugerencias adecuadas de manejo, en periodos específicos, garantizando así la supervisión por personas calificadas. Se trata de resaltar algunos aspectos del desarrollo susceptibles de ser observados y manejados en la vida cotidiana que facilitarán la educación en salud y desarrollo de la familia.

La propuesta incluye parámetros conductuales agrupados en funcionamientos observables por los padres en el contexto de la vida diaria. Se enfatizan las secuencias, enmarcadas en etapas relativas a intervalos de edad, sin atribuirlas a edades específicas de adquisición, ante sus variaciones temporales en diversas poblaciones. Se destacan condiciones del ambiente que pueden limitar o restringir el desarrollo y signos de alarma que obligan a considerar una evaluación cuantitativa del neurodesarrollo con la aplicación de una evaluación diagnóstica. ${ }^{6}$

Observar y promover el desarrollo de los niños es condición fundamental para un desarrollo saludable, sin la angustia por mediciones cuantitativas relacionadas con conductas en edades específicas. Tratamos de exponer una visión clínica en la práctica cotidiana del pediatra, con énfasis en el desarrollo infantil, ante las necesidades asistenciales que imponen estar alertas sobre la enfermedad, dejando parcialmente de lado las necesidades de los padres de información sobre cómo llevar a cabo la supervisión y conducción del desarrollo de sus hijos, haciendo que en la práctica el pediatra se vea en la necesidad de atender llamados constantes ante dudas en el manejo de los niños.

Las conductas a evaluar dentro del grupo de funcionamientos seleccionados se incluyeron por la facilidad de su observación, tanto por el médico como por los padres y porque se pueden constituir en problemas que conducen, de no identificarse en los periodos de edad considerados, a desviaciones del desarrollo esperado. Estos periodos se establecieron con base en investigaciones sistemáticas en poblaciones de niños de bajo riesgo perinatal que provienen de la zona metropolitana y de zonas del centro de la República.2,6 Siendo amplia la variabilidad de presentación de las conductas los periodos se consideran dentro de sus límites máximos de normalidad. Es importante tenerlos siempre en mente y estar atentos ante signos tempranos alarma que nos indiquen, antes de concluir el periodo límite de adquisición de una conducta, que una secuencia no está organizándose en forma adecuada, de manera que el pediatra pueda emitir las recomendaciones oportunas para evitar las desviaciones $y$, de considerarlo necesario, remitir al paciente con el especialista indicado una vez identificada la causa de esta desviación potencial.

Algunos comportamientos incluidos requieren de su observación e incluso su inducción por el pediatra, pero los comportamientos derivados de tipo voluntario son susceptibles de registrase por el cuidador principal del niño. 
Es importante recordar que cualquier periodización de funciones y conductas es arbitraria, ya que corresponden a grandes sistemas funcionales que se relacionan entre sí, dando paso a conductas entendidas como acciones con dirección. No es de extrañar por tanto que se imbriquen de forma constante.

La periodización es útil para describir las conductas correspondientes a cada grupo de funcionamientos y para detectar las condiciones ambientales adversas que pueden limitar el desempeño de los niños. Debe considerarse que la vigilancia del desarrollo es un proceso. Las recomendaciones sugieren evaluaciones periódicas del desarrollo implementando procedimientos sistemáticos, al menos una vez por semestre, aunque comentar los avances del desarrollo debe ser una práctica continua en cada valoración del pediatra o del equipo de salud..$^{5,7}$

No pretendemos restar importancia ni reemplazar las pruebas de tamizado, existen varias al alcance del pediatra como Denver $11,{ }^{8} \mathrm{CAT}-\mathrm{CLAMS}^{9}$ o elVANEDELA; este último creado especialmente para la población mexicana. ${ }^{10}$ Proponemos aplicarlas con esta visión amplia, integral y promotora, sin perder de vista las secuencias sobre las que subyacen los hitos que éstas evalúan y situando al niño en su entorno cotidiano. Ese proceso se verá facilitado si se interpretan indicadores del desarrollo a la luz de una comprensión de los procesos adaptativos esenciales reconocibles y referibles por sus cuidadores. En aquellos casos en que el pediatra se vea limitado para aplicar una prueba tamiz por las demandas asistenciales, habituarse a incorporar estas orientaciones enriquecerá y tornará más efectivas la vigilancia y la promoción del desarrollo.

\section{CERO A CUATRO MESES DE EDAD}

Regulación interna y organización de ritmos

El punto de partida para un desarrollo adecuado es la estabilidad del medio interno y la organi- zación de algunos ritmos de control automático. La regulación del medio interno permite ajustes hacia el medio externo y provee un estado óptimo para establecer interacciones más complejas, logrando asimilar e integrar conductas nuevas. Los principios generales del desarrollo en este grupo de comportamientos implican su estabilidad ante la manipulación al paso del tiempo y su capacidad de habituación ante la repetición.

Los automatismos neurovegetativos como la respiración, frecuencia cardiaca control hemodinámico, regulación de la temperatura y el tono muscular, requieren supervisión. En este periodo se organizan comportamientos más complejos como los ciclos sueño-vigilia, a partir de periodos cortos de vigilia en el día y la noche que paulatinamente se transforman en periodos más prolongados de vigilia en el día y periodos de sueño continuo, sin demandar alimento durante 5 o 6 horas por la noche. La búsqueda y la succión-deglución, coordinadas con la respiración, son eficientes desde los primeros días del nacimiento. La succión posteriormente se va regulando hasta detenerla a voluntad ante estímulos novedosos del ambiente. Los cambios secuenciales en las frecuencias cardiorrespiratorias, en la regulación térmica y en los ciclos sueño-vigilia en este periodo son ampliamente conocidos por los pediatras. ${ }^{11}$

Vigilar la presencia y calidad de reflejos primitivos como el de Moro y tónicos laberínticos, presentes desde el nacimiento, es un punto relevante ya que modulan el tono postural de acuerdo con los cambios de posición en los que se coloca al niño. El tónico asimétrico de cuello que facilitará los cambios de posición para rodarse puede observarse en los decúbitos y dará paso, al inicio, a algunas respuestas posturales que se constituyen posteriormente como infraestructura de conductas de defensa o retirada más tardías. Prensión palmar, reacción de Bauer, marcha automática y colocación de manos y pies deben evaluarse vigilando su presencia, simetría y evo- 
lución en el tiempo. En condiciones saludables estas reacciones reflejas tienden a habituarse y no se presentan después de varias repeticiones. Los padres pueden observarlos en forma de atrapamientos posturales, indicados más adelante como los signos de alarma, generalmente la familia lo refiere.

Condiciones socioambientales adversas al desarrollo: manipulación excesiva, vestimenta inapropiada para la temperatura ambiental, exceso de estímulos luminosos o sonoros, falta de higiene corporal, alimentación sin ritmos asociada con cualquier manifestación de Ilanto sin atención a necesidades diversas, colocación en una sola posición sin cambios, falta de estímulos afectivos, zarandeo constante o brusco. Ambientes contaminados, oscuros o de frio intenso. Introducción temprana de otros alimentos dañinos o contraindicados.

Recomendaciones: deben ir encaminadas a lograr la organización de ritmos en la alimentación mediante horarios regulares con estrategias que garanticen la ingesta de la cantidad adecuada por toma, conforme reglas generales de capacidad gástrica y características de cada niño. Respecto al sueño son relevantes los periodos de luz u obscuridad para la organización de lapsos regulares para la diferenciación del día y la noche. El establecimiento paulatino de rutinas de cuidado (alimentación, baño, juego, sueño) con reglas en los horarios promueve la formación de hábitos.

Signos de alarma: apneas, acrocianosis, dificultades para succionar o deglutir coordinadamente o para conciliar el sueño; hipertono (se percibe "duro" o "tieso", "no se acurruca al cargarlo"), postura en opistótonos, manos empuñadas con pulgar atrapado; hipotono (posición de rana o extensión flácida; combinación de hipotono axial e hipertono extensor con miembros inferiores en tijera y pies en punta y más adelante retraso en el sostén cefálico; reacción intensa de Moro ante estímulos mínimos, atrapamiento en cualquier postura refleja.

\section{Las emociones y los sentimientos}

El desarrollo emocional del recién nacido está íntimamente ligado a sus requerimientos y a la sensación de bienestar al tenerlos satisfechos. Las experiencias afectivas y calidad del cuidado materno, sumadas a las características propias del niño, modifican su potencial para autorregularse y crecer en armonía. La seguridad y habilidad en el manejo y la implementación de rutinas disminuyen el estrés ante los cambios y favorecen el inicio de conductas como la expresión de sentimientos dirigidos al cuidador mediante Ilanto o risa, la respuesta a la voz, el acomodarse al regazo materno y la habituación paulatina a los estímulos del ambiente.

Condiciones socioambientales adversas al desarrollo: insuficientes medidas de afecto expresadas por rechazo a alimentarlos en el regazo, falta de modulación en la voz del cuidador, rehuir expresiones de afecto, falta de contacto corporal, retrasos severos en la atención a las necesidades básicas en cualquiera de sus modalidades, ausencia de contacto visual o respuestas a las vocalizaciones o sonrisas tempranas del hijo.

Recomendaciones: manejo oportuno de las necesidades, proveer contención y seguridad favoreciendo la interacción durante las actividades del día. Evitar apresuramientos para atender las necesidades del niño sin indagar sobre sus demandas reales (identificación de tipo de llanto o gestos o sonidos) de forma que con afecto y medida se promueva la tolerancia y el autocontrol.

Signos de alarma: sobresaltos al hablarle, ausencia de respuesta a la voz de la madre, irritabilidad excesiva, que no se acomode al regazo materno 
o que no responda con mirada, balbuceos o sonrisas cuando se le habla.

\section{El movimiento}

Gracias al movimiento el niño descubre su cuerpo y mediante la experiencia aprende a utilizar todas sus partes con un objetivo. Inicialmente los movimientos son automáticos, libres y desordenados. Mueve los ojos siguiendo parcialmente caras, ve sólo una pequeña parte del mundo que lo rodea sin enfocar. Mueve boca, lengua y cabeza buscando el pecho materno, succiona sus manos si están cerca de la boca. La sonrisa es automática. Posteriormente inician los movimientos dirigidos, se lleva las manos a la boca, controla su cabeza, sigue y toma objetos primero a los lados con una mano, luego en línea media. Intenta chupar todo lo que ve y toca, comienza a sacudir una sonaja y finalmente logra soltarla. Hay expresiones faciales ante su satisfacción o placer.

Condiciones socioambientales adversas al desarrollo: mantener al niño en posiciones fijas sin oportunidad de mover tronco o cabeza en diferentes posturas (posiciones supina, prono laterales o incorporación a sentado), sujetar brazos y piernas en posición rígida. Colocar al niño en la misma posición por largo tiempo y sin variaciones respecto a los estímulos ambientales.

Recomendaciones: permitir el libre movimiento de extremidades, colocarlo ocasionalmente en posición prona en el día, contener reacciones de sobresalto cuando sea pertinente ajustando de forma suave brazos flexionados cerca de la boca. Incitar los movimientos de las extremidades superiores con agarre voluntario, de lateral hacia la línea media

Signos de alarma: movimientos asimétricos, hipoactividad en general o de alguno de sus miembros, temblores exagerados o movimientos reptiformes al alcanzar un objeto, limitaciones y retraso en la adquisición de los movimientos iniciales dirigidos de forma voluntaria.

La mirada

Es un elemento fundamental para el desarrollo de la atención y una ventana para favorecerla desde las etapas más tempranas. El 80\% de la información del medio en el primer año de vida llega por los ojos y a través de la mirada comunicamos interés, rechazo, fatiga, etcétera. Inicialmente el niño busca en forma refleja la luz, establece contacto con la cara de la madre durante la alimentación, comienza posteriormente a seguir rostros al frente y que se desplazan lateralmente cada vez a mayor distancia de su cara. La atención inicial a las caras comienza a generalizarse a objetos que explorará primeramente con los ojos y posteriormente logrará tomarlos al conjugar la vista con el movimiento de las manos. Comenzará a buscar con la mirada orientándose cuando le hablan o escucha sonidos familiares.

Condiciones socioambientales adversas al desarrollo: fallas de contacto visual del cuidador principal, ambientes "planos" sin estímulos luminosos o coloridos en el ambiente, escasa verbalización del cuidador que no mantiene la atención del niño en las caras, o falta de demandas para la fijación visual al ofrecerle objetos prensiles o móviles.

Recomendaciones: buscar intencionalmente el contacto visual, platicándole mientras se le da de comer y en momentos en que se le vea bien dispuesto. Posteriormente jugar a mostrarle juguetes con y sin sonido que le sean atractivos y que más adelante podrá tomar.

Signos de alarma: ausencia de fijación a cara u objetos que se presentan, ausencia o asimetría en el seguimiento, evasión del contacto visual. 
Escuchar, atender y conversar

La capacidad de escuchar y paulatinamente ir asimilando los sonidos del lenguaje materno favorecen la relación con los demás, benefician también la modulación emocional del niño que se orienta por el tono, el ritmo y la armonía de las voces que escucha. A través de la voz, principalmente la de la madre, se facilita la atención del niño y se logra que dirija su mirada hacia la fuente sonora.

Desde el nacimiento el niño escucha despierto o dormido, respondiendo a eventos de su entorno. Los sonidos lo alertan. La voz materna es el primer sonido que reconoce, el más importante y atractivo, se calma al escucharla. Emite espontáneamente algunos sonidos, balbucea y de forma paulatina comienza a responder con sonidos guturales y sonrisas a los diálogos que el cuidador provoca, siendo sensible a los tonos de la voz. Aprende a identificar emociones por los cambios en el tono respondiendo acorde con ellos, con sonrisa o llanto. Hacia el final de esta etapa voltea cuando se le habla.

Condiciones socioambientales adversas al desarrollo: no se le habla directamente al niño y no se busca o mantiene su mirada al hacerlo, no se le arrulla, no se modula la voz según cambios afectivos, se mantienen muchos estímulos sonoros al mismo tiempo especialmente de alta intensidad. ${ }^{12}$

Recomendaciones: favorecer el diálogo con el bebé, utilizar cambios de tono y modulaciones acompañados de expresiones faciales conforme a las diferentes emociones a expresar. Dar tiempo a que responda y escucharlo. Evitar someterlo a gritos, ruidos demasiado fuertes o que le ocasionen sobresaltos o lo irriten tornándolo más susceptible o llorón.

Signos de alarma: no reacciona ante sonidos fuertes; no busca y localiza la fuente de sonido, no sonríe ni muestra interés cuando le platican o cantan. Emite escasos sonidos.

\section{La inteligencia}

Las reacciones reflejas innatas que presenta el niño al nacer lo predisponen para adquirir conocimientos mediante la interacción con otros. El niño es capaz de incorporar y utilizar las experiencias y estímulos que le son presentados de forma equilibrada, progresando en la construcción del pensamiento al diferenciarlos, entenderlos y emplearlos para resolver diferentes situaciones. Desde etapas tempranas el niño es un explorador activo y corresponde a los cuidadores proporcionar un medio seguro y propicio dicha exploración.

Inicialmente ejercita la fijación, seguimiento, búsqueda, succión y prensión. Comienza a interesarse por detalles de las caras y objetos, atiende preferentemente a la madre, después al resto de la familia. Su actividad se modifica cuando algo Ilama su atención.

"La práctica hace al maestro". Al repetir situaciones dentro de rutinas cotidianas se establecen hábitos que para la inteligencia representan estrategias de aprendizaje. Al observar y atender los movimientos y los sonidos que anteceden actividades cotidianas como el ruido del agua antes del baño, la preparación de alimentos antes de darle de comer, la caja de juguetes antes del juego, la canción antes de dormir, comenzará a anticipar lo que le espera, mostrando su interés y relacionando los actos con gestos o sonidos que se implican en estos intercambios. La capacidad de anticipar favorece el autocontrol al reconocer que sus necesidades serán atendidas cuando comienza una rutina. Podremos observar en esta etapa excitación a la hora de la alimentación, inquietud en los horarios de sueño, habituación a estímulos ambientales como cambio de ropa o baño. Inicio de intencionalidad: ve sus ma- 
nos, las reconoce como propias y las lleva a la boca para autoconsolarse, también lo hace con objetos. Emite sonidos vocales y guturales en respuesta a la interacción como un acto intencional.

Condiciones socioambientales adversas al desarrollo: para la formación de la mente donde el pensamiento y el lenguaje son elementos fundamentales y sustrato en la construcción de la inteligencia sensoriomotriz. La capacidad receptiva visual, auditiva y sensorial, así como el movimiento son requisito, cualquier limitación del medio que no favorezca su desarrollo retrasará su organización. La falta de motivación afectiva es otra fuente importante para el retraso de este tipo de inteligencia inicial. La falta de rutinas de cuidado restringirá la posibilidad de generar conductas anticipatorias de eventos, siendo este un mecanismo primordial para el desenvolvimiento de otros mecanismos mentales. Las limitaciones en las interacciones sociales efectivas, ambientes pobres de estímulos o sobreprotección con restricciones para el autocontrol, resumen condiciones adversas para su desarrollo.

Recomendaciones: satisfacer de forma oportuna y pertinente las necesidades del niño, implementando rutinas horarias con cierta flexibilidad, de acuerdo con las necesidades de la familia e interactuando conforme cada proceso de cuidado. Permitir libertad de movimientos, chupar manos y objetos. Presentar variedad de experiencias en posturas, tonos de voz, objetos. Brindar al niño la oportunidad de hacer por sí mismo aquello que esté en sus posibilidades, evitando la frustración y retándolo para avanzar conforme crece.

Signos de alarma: no busca la mirada o no intenta tocar el pecho materno o biberón. Rechaza ciertos sonidos u objetos. No se mueve ni trata de alcanzar los objetos. No identifica rostros familiares. Produce escasos sonidos y balbuceos o éstos son monótonos o estereotipados.

\section{El juego y la creatividad}

Los primeros juegos que el niño desarrolla dependen de la interacción visual y verbal: mira los rostros, escucha la voz de los padres, posteriormente sonríe y produce sonidos (balbuceo precanónico). Mueve libremente brazos y manos, piernas y pies, tocando su boca, explorando azarosamente su cuerpo y lo que le queda cerca. Todo movimiento y experiencia novedosa que le cause sensación de placer se convierte en juego y éste en la forma de asimilar las características del medio, induciéndolo y retándolo para adquirir nuevas formas de exploración y aproximación al mundo real, que en el futuro producirán las abstracciones necesarias para enriquecer su fantasía, imaginación y creatividad. Pronto mira $y$, al buscar los objetos sonoros que escucha, desarrolla el gusto por aquellos objetos que puede tomar y agitar iniciando las acciones de repetición con las que ejercita el control de su cuerpo y sensaciones diversas.

El juego de interacción cara a cara con el cuidador, conforme el niño crece, es otra estrategia de regulación del comportamiento ya que la sonrisa, los gestos y las diversas expresiones faciales de los padres logran disminuir el Ilanto, manteniendo y prolongando la atención en los períodos de vigilia. Para el niño este tipo de interacciones se transforma en una condición de aprendizaje lúdico, desde las primeras semanas de vida.

Condiciones socioambientales adversas al desarrollo: poca disposición de los padres al juego, subvaloración de la importancia del juego, limitación de las interacciones cara a cara por padres que no vocalizan o gesticulan al atender al niño o cuidadores múltiples con prisa o poca sensibilidad a las necesidades. Dejar al niño rodeado de objetos sin favorecer su juego mediante mediación de interacciones humanas. Interrumpir o ser excesivamente directivos en sus juegos o 
cambiarlo de forma constante sin considerar el interés o la atención del niño.

Recomendaciones: favorecer el juego visual y verbal desde las primeras etapas. Presentarle un juguete adecuado a su edad a la vez, permitiendo su exploración. Evitar hacerle cosquillas, aventarlo hacia arriba o arrullarlo en sentido vertical. Propiciar juegos de exploración del rostro de los familiares con cambios de expresiones, gestos y contacto con las manos, respuesta alterna a sonidos, manipulación y exploración de objetos con consistencias y texturas diversas, o que producen eventos interesantes simples.

Signos de alarma: no responde a interacciones verbales o de objetos. No se interesa por juegos o juguetes.

\section{CINCO A NUEVE MESES DE EDAD}

La regulación interna y la organización de ritmos

La succión se diferencia de la deglución y la prensión se torna voluntaria; el niño organiza periodos de sueño más largos por la noche (6 a 10 horas continuas) y de vigilia en el día. Desaparecen el reflejo tónico asimétrico de cuello en supino y la marcha automática. Se puede desencadenar el reflejo tónico simétrico de cuello al Ilevarlo a sentado, reflejo que facilitará enderezar la cabeza desde el decúbito y llegar a la posición de sentado tirando de sus brazos. Las respuestas posturales son más activas y aparecen reacciones de equilibrio y defensa en posición sedente.

Condiciones socioambientales adversas al desarrollo: mantenerlo en posturas con poca modificación, restringiendo la intencionalidad para que el niño las adquiera por sí mismo. Mantener ritmos horarios desordenados, sin formación de hábitos. No respetar horarios de sueño, especialmente por las noches.
Recomendaciones: continuar con el establecimiento de rutinas y hábitos para la alimentación, sueño, higiene y juego. Considerar características propias del niño al iniciar la ablactación como tono bucal, coordinación con respiración, tolerancia a consistencias y sabores diferentes.

Signos de alarma: no se observa mayor organización general en el establecimiento de ciclos de sueño o alimentación. Se atraganta al comer o no acepta consistencias semisólidas. Persistencia de reflejos primitivos (propios de la etapa anterior como el Moro o los reflejos tónicos) sin dar paso a organización de conductas voluntarias y más complejas. Movimientos estereotipados constantes, hiperactividad o que se avienta hacia atrás.

Las emociones y los sentimientos

Inicia el manejo social de expresiones: Ilanto ante la necesidad y el estrés y sonrisa espontánea ante interacción y estímulos placenteros. Su rostro muestra alegría, enojo o miedo conforme a expresiones familiares. Regula su actividad con cambios de vOz y la claridad de señales maternas. Ríe a carcajadas. Espera por periodos breves a que se le atienda. Se entretiene más al jugar. Se consuela solo y llora menos.

Condiciones socioambientales adversas al desarrollo: rutinas de cuidado poco saludables al generar dependencias emocionales sin control, ignorar situaciones de ansiedad o ejercer fuerza física para controlarlo, gritarle o dejarlo solo. No responder a las demandas afectivas del niño sustituyéndolas por recompensas materiales. Pobre tolerancia a las expresiones de enfado o berrinche del niño. Violencia intrafamiliar o condiciones de perturbación en la salud mental materna.

Recomendaciones: explicar a los padres que desde bebés los niños son capaces de entender lo que se les indica, por lo que deben controlarse los be- 
rrinches manteniendo reglas firmes que cumplan todos los miembros de la familia, por ejemplo que no golpeé o jale el cabello mediante indicaciones de respeto y cariño. Regular la insistencia en realizar acciones peligrosas o no deseables mediante distracciones, evitando gritos, rechazo, golpes o largos discursos. Respetando horarios de comida, sueño, higiene y juego, aprenderá a ajustar sus necesidades y comenzará a expresar de diversas formas sus demandas (se inquieta, hace gestos, señala lo que quiere).

Signos de alarma: no sonríe. No mantiene el contacto visual. No le gusta que lo carguen. Llora mucho, se "priva". No muestra expresiones emocionales.

\section{El movimiento}

Rueda de prono a supino y después a la inversa. Al empezar a cambiar de posición por su cuenta reconoce nuevos objetos e intenta alcanzar, tomar y chupar todo lo que le queda cerca. Alcanza sus pies. Explora a través de las manos las caras y los juguetes. Toma objetos con dos manos en línea media y sus movimientos se tornan más certeros. Al sentarse, explora los objetos tomándolos con toda la palma primero y posteriormente, mediante la pinza. En prono levanta cabeza y tronco, después gira a los lados y se impulsa hacia atrás. Inicia el apoyo en cuatro puntos.

Condiciones socioambientales adversas al desarrollo: dejar al niño en sitios de riesgo o expuesto a quemaduras, lesiones, caídas o golpes. Espacios domiciliarios muy restringidos, insalubres, ausencia de juguetes u objetos que el niño pueda tomar y explorar. Dejar a su disposición juguetes no apropiados para su edad, con piezas desprendibles que pueda ingerir, golpearse, cortarse o que ofrezcan algún riesgo.

Recomendaciones: brindar oportunidades para permanecer sentado y desplazarse en el piso. Es muy importante recalcar a los padres los riesgos de caídas y accidentes al incrementar el desplazamiento; concientizarlos de la importancia de proveer un entorno seguro.

Signos de alarma: tendencia a aventarse hacia atrás constantemente. Preferencia manual permanente en sus acciones, carga asimétrica de peso en el sentado, asimetría en el movimiento, ya sean rodamientos, giros, arrastre, etcétera. Retraso en la adquisición de conductas esperadas. Realiza todas las acciones motoras de manera azarosa. Gran actividad: se mueve continuamente. Hipomovilidad, movimientos rígidos o retorcidos. Actitudes posturales de mano empuñada, piernas en tijera, pronación de brazo, posición de candelabro o rendición en los brazos.

La mirada

Mantiene interés y atención en un objeto a la vez. Mira y toma lo que está a su alcance y se fija dónde lo suelta. Observa objetos sentado siguiendo con ojos y cabeza lo que se desplaza a su alrededor y es capaz de ver objetos pequeños que comienza a tomar con la mano mediante barridos.

Condiciones socioambientales adversas al desarrollo: presentar estímulos poco atractivos y poco variados, "planos" o monótonos. Rodear al niño de estímulos excesivos que no le permitan explorar cada uno de forma detenida. No proveer espacios que amplíen su campo visual, iluminación escasa. No mantener la atención del niño con la mirada, no utilizar señales gestuales para indicarle cosas, acciones, estados de ánimo. No responder a la mirada conjunta cuando propicia que el adulto le acompañe en lo que ve.

Recomendaciones: colocar al niño en lugares y posturas con un amplio campo de visibilidad. Realizar juegos de seguimiento visual que favo- 
rezcan prolongar los periodos de atención. Dar oportunidad de explorar un juguete u objeto a la vez.

Signos de alarma: estrabismo, no explora los objetos que toma o no sigue el movimiento, dismetrías; parece no observar objetos pequeños, inclina la cabeza para ver cosas que tiene enfrente.

\section{Escuchar, atender y conversar}

Atiende a sonidos nuevos, voltea cuando lo llaman por su nombre, se mueve al ritmo de la música, se ríe o carcajea ante sonidos novedosos, observa el movimiento de la boca cuando le hablan, vocaliza e inicia bisílabos. Imita algunos sonidos, confiere entonación variada. Juega con los sonidos para escuchar su propia voz.

Condiciones socioambientales adversas al desarrollo: interacciones verbales muy limitadas con el cuidador. No buscar y mantener la atención del niño con la mirada mientras se le habla. Emplear un lenguaje pobre, repetitivo, restrictivo y sin contenidos direccionales de las acciones del niño. No mantener la comunicación ida y vuelta entre cuidador y niño.

Recomendaciones: favorecer la comunicación verbal. Relatarle al niño lo que se hace durante su cuidado nombrando las diferentes partes del cuerpo y algunos objetos por su nombre en las rutinas de la vida cotidiana. Promover la organización espacial del cuerpo y el conocimiento de palabras y significados. Es conveniente inicialmente usar los mismos términos para denominar lo que se señala sin crear confusiones. El uso del "no" introduce las primeras reglas que deben ser elegidas y aplicadas con constancia para que logre asimilarlas; no se recomienda su empleo ante cualquier circunstancia.

Signos de alarma: no voltea cuando le Ilaman por su nombre; no se tranquiliza con la voz. Pa- rece que no escucha lo que se le dice mientras realiza una actividad. Se mueve rítmicamente sin modificar el movimiento a pesar de distraerlo. No parece comprender las reglas elementales.

\section{La inteligencia}

Intenta nuevas acciones: toma, suena, golpetea, jala. Explora los objetos visual y auditivamente prolongando el juego. Comienza a reconocer nuevos objetos y ajusta las acciones a sus características (agita la sonaja, toca el tambor). Identifica características de los elementos del ambiente como textura, consistencia, sabor o color mostrando preferencias y rechazos por comidas, juguetes u otros objetos. Replica algunos gestos con partes de su cuerpo que puede ver (decir adiós, aplaudir). Reconoce expresiones de felicidad o disgusto en otras personas. Comienza a construir su conciencia al recordar y relacionar que las cosas están y permanecen aunque no las vea, escuche o toque; busca la cara de la madre u objetos que se le esconden o se le caen. Desarrolla esquemas nuevos para usar las partes de su cuerpo y realizar acciones como sacar y meter, desplazarse o levantar los brazos. Anticipa cada vez más mostrando interés, gusto o rechazo por lo que sabe que sucederá.

Condiciones socioambientales adversas al desarrollo: Cualquier restricción que limite el movimiento, la visión, la exploración activa de los objetos, de expresión de afectos, de las interacciones comunicativas, especialmente durante el juego de interacción entre cuidador y niño.

Recomendaciones: los padres deben dejar que el niño realice las cosas por sí mismo, no intentar satisfacer todas sus inquietudes sustituyéndolo, darle oportunidades y proporcionar sólo el apoyo necesario para conseguir sus objetivos infantiles, con el justo apoyo para evitar la frustración. Permitir la exploración de los objetos de la vida cotidiana que no representan riesgos. Indicar 
verbalmente las actividades que se ejecutan con su cuerpo e indicarle lo que se espera de su parte. Propiciar que realice las actividades en los sitios adecuados de forma que aprenda a respetar normas: comer sentado en la mesa, lavarse manos en el baño, etcétera. Los juegos de imitación, esconder cosas, ensartar formas e identificar imágenes favorecen la inteligencia a esta edad.

Signos de alarma: rehúsa ciertos sabores o consistencias, sonidos u objetos. Los objetos le son indiferentes, no les presta atención ni trata de alcanzarlos. No imita lo que se le muestra. No reconoce rostros familiares. Retrasa organizar praxias como sacar, meter, arrastrar, chocar.

\section{El juego y la creatividad}

Desarrolla esquemas o praxias como el chupar, morder, golpear, agitar y jalar. Juega con la comida. Prueba todo lo que le queda cerca y contempla el resultado de sus actos. Comprende el anverso de un objeto: voltea la mamila o un muñeco si se pone de cabeza.

Condiciones socioambientales adversas al desarrollo: sustituir o apoyar al niño en exceso, ignorando sus pequeñas propuestas de juego con los objetos, caras o tipos de comunicación.

Recomendaciones: presentarle un juguete a la vez y motivarlo a explorarlo ampliamente. Proveer juguetes de diferentes tipos apropiados a su edad. Jugar con el niño dando prioridad a su juego espontáneo sobre los intereses o inquietudes de los padres. Los padres deben propiciar espacios de juego, propiciar las conductas de exploración del medio, el disfrute dando seguridad al niño cuando se plantea situaciones placenteras.

Signos de alarma: juega con un solo juguete y de forma repetitiva. No participa en los juegos que se le proponen. Juega constantemente con un movimiento específico (balanceo). Se muestra extremadamente inseguro para iniciar nuevas situaciones de juego.

\section{DIEZ A DOCE MESES DE EDAD}

La regulación interna y la organización de ritmos

Al comer mastica y acepta diferentes texturas en los alimentos, toma líquidos sin atragantarse. Duerme 10 a 12 horas por la noche y por el día se mantiene despierto y activo por mayor tiempo. Realiza una a dos siestas. Las reacciones de paracaídas están presentes.

Condiciones socioambientales adversas al desarrollo: mantener hábitos alimenticios de edades previas sin variación, dejar de lado rutinas horarias de sueño, juego, higiene, actividades etcétera.

Recomendaciones: introducir alimentos picados. Propiciar actividades que prolonguen su atención. Mantener rutinas y establecer horarios regulares para la comida, el sueño, juego y aseo.

Signos de alarma: no logra dormir toda la noche. Le es difícil dormir siestas en el día. Se sobresalta con los ruidos. No para de moverse todo el día incluso a altas horas de la noche, no se cansa nunca.

Las emociones y los sentimientos

Maneja expresiones emocionales para consolidar sus interacciones. Muestra enojo o enfado cuando no le permiten hacer lo que desea y disfruta claramente con risas y juegos cuando le permiten hacer cosas por sí mismo. Reconoce a sus cuidadores y responde mejor a ellos que a extraños. Muestra francas preferencias por los miembros de su familia. Se sobresalta por condiciones diferentes a su entorno habitual pero puede regular su Ilanto mediante otras formas de expresión para pedir protección. Percibe algunos peligros. 
Condiciones socioambientales adversas al desarrollo: dejar al niño sin control en sus expresiones de enojo, rechazo o negación. Limitar sus expresiones espontáneas de afecto. Dejar que dañe los objetos, que agreda a los miembros de la familia o cualquier manifestación de agresión hacia las personas o hacia sí mismo.

Cuando se le ha educado y ha integrado a su conducta los horarios de comida, sueño e higiene, aprende a ajustar esas necesidades y a expresar de formas diversas sus demandas conforme el medio las vaya modificando. Va entendiendo el establecimiento de límites y reglas.

No todos los niños son iguales. Hay bebés más activos o más tranquilos. Identificar tempranamente el tipo de ritmo que establece y la intensidad de sus expresiones permite modular su atención y modular sus comportamientos posteriores, logrando una mayor variedad y menor ímpetu en las expresiones, disminuyendo los berrinches y "pataletas" con mayor perseverancia y tolerancia ante la frustración.

Recomendaciones: constancia en el establecimiento de rutinas, reglas y límites. Evitar que el Ilanto se convierta en la forma mediante la cual el niño obtiene lo que desea. Presentar dentro de las actividades cotidianas retos acordes con su edad y promover su resolución de acuerdo con sus habilidades.

Signos de alarma: sus formas de expresión se ven limitadas, es difícil identificar sus intereses. Hace berrinches hasta "privarse". No desconoce a los extraños. Se agrede a sí mismo. Parece como "si estuviera perdido cuando se le habla".

\section{El movimiento}

Dirige sus movimientos a metas con mayor precisión. Explora su entorno mediante el arrastre y el gateo. Se para e inicia marcha sostenido, llega a dar pasos solo. Consolida praxias de jalar, soltar, arrastrar, golpear, meter y sacar. Avienta todo y observa su recorrido buscando anticiparlo. Toma pequeños objetos con facilidad.

Condiciones socioambientales adversas al desarrollo: la familia no amplía los espacios para el movimiento del niño y su juego exploratorio (parques, jardines, etcétera). Limitar la actividad exploratoria. Sustituir las acciones del niño dándole los objetos de su interés sin que los busque, complete maniobras o haga cualquier cosa por sí mismo, por temor a que se ensucie, se caiga o se golpeé.

Recomendaciones: continuar propiciando la posición prona y el gateo. Limitar las zonas de acceso peligroso para el niño, dejar recorrer los espacios que desee y adecuarlos para su seguridad. Brindarle apoyo e indicarle verbalmente lo que se desea realice o complete para lograr por sí mismo conseguir objetos de su interés.

Signos de alarma: retraso en la adquisición de conductas. Demasiada actividad; no logra permanecer sentado durante las comidas, algún juego o cualquier otra acción. Asimetrías constantes en su movimiento o preferencia manual franca.

La mirada

Interpreta gestos y miradas de sus cuidadores. Observa las tareas que realiza con sus manos y explora los objetos de diferentes formas logrando prolongar sus periodos de atención. Avienta objetos y sigue sus trayectorias. Disfruta ver libros o fotografías y descubre detalles de sus juguetes que no había observado, con lo cual el aspecto cognitivo y lingüístico dará un avance relevante.

Condiciones socioambientales adversas al desarrollo: Dejar al niño por su cuenta sin favorecer su atención y sus interacciones, no indicarle 
verbalmente lo que observa, espacios con campo visual limitados, material visual escaso (libros, imágenes); falta de atención por el cuidador a la relación visual que el niño establece con los objetos, no se propicia la mirada conjunta o el mirar a los ojos cuando se le habla.

Recomendaciones: Ilamar su atención y mirarlo a los ojos al darle indicaciones y hablarle. Permitir la exploración de un objeto a la vez. Ver libros con pocas imágenes observando sus detalles y hablándole sobre ellas. Implementar juegos de observación e imitaciones sencillas.

Signos de alarma: evita el contacto visual, no explora con mayor detenimiento. Se acerca mucho para localizar objetos pequeños. No muestra interés por las imágenes de un libro.

\section{Escuchar, atender y conversar}

Al escuchar con atención y comprender información verbal básica comienza a seguir indicaciones: ven, dame, ten. Entiende gestos y los imita. Parlotea constantemente. Replica movimientos asociados con cantos y juegos infantiles. Señala elementos del medio que Ilaman su atención y objetos y partes de su cuerpo cuando los nombran. Busca imitar el sonido de palabras familiares logrando decir las primeras. Localiza visualmente a personas conocidas cuando se les nombra.

Condiciones socioambientales adversas al desarrollo: no se solicita su mirada para hablarle, no se establecen diálogos con el niño o se dan instrucciones restrictivas de forma constante. No se favorece su gesticulación, imitación o sus respuestas verbales.

Recomendaciones: nombrar los elementos del medio, partes de su cuerpo y de los demás: cuidador, hermanos, muñecos, así como las acciones cotidianas al realizarlas. Dar indicaciones verbales sobre lo que se hace o espera de él y no sólo dirigir o restringir conductas físicamente. Atender sus conversaciones y favorecer su expresividad.

Signos de alarma: parece que no atiende. No habla. Ante más de un estímulo (juguete, persona, ruido) se desorganiza, no termina las actividades.

\section{La inteligencia}

Experimenta con las nuevas praxias adquiridas e intenta anticipar lo que sucede al modificar sus acciones. Se orienta en sus espacios, conoce la ubicación de cosas o personas de su interés, de forma que el gateo y la marcha son más efectivos al dirigirse a una meta. Emplea nuevos medios para alcanzar un fin, jalando manteles o tapetes para atraer objetos, tirando o arrastrando bancos $\mathrm{u}$ otro aditamento en el intento de alcanzar objetos. Aprende a distinguir lo que es un juguete de lo que no lo es. Sabe con lo que puede jugar y lo que no debe tocar. Imita acciones con partes de su cuerpo que no puede ver: hace "ojitos" o cara de monstruo.

Condiciones socioambientales adversas al desarrollo: esperar que el niño sólo se interese por sus juguetes y no por los objetos y cosas del medio, restringiéndole la exploración del mundo real, la comida, los adornos de una casa, etcétera.

Recomendaciones: permitirle realizar por sí mismo tareas de la vida cotidiana: quitarse el calcetín, proporcionar prendas u objetos, comer. No satisfacer sus inquietudes sin brindarle previamente oportunidad de expresarlas y alcanzarlas por sí mismo.

Signos de alarma: no integra nuevas praxias al explorar los objetos como aventar, meter, sacar, jalar. No comprende expresiones como: ten, dame, pon. No imita. No muestra preferencias. 


\section{El juego y la creatividad}

Amplía su radio de acción. Se entretiene por tiempos mayores. Comienza con juegos de reciprocidad como impulsar una pelota y esperar a que se la devuelvan, además de la repetición y ajustes a las praxias ya mencionadas. Intenta replicar canciones y juegos que se le enseñan con vocalizaciones y gestos.

Condiciones socioambientales adversas al desarrollo: los padres o cuidadores imponen el juego sin brindar al niño oportunidad de modificarlo a su gusto.

Recomendaciones: favorecer la imitación con juegos y cantos, proveer juegos de apilar, meter, sacar, ensartar, peinar a los muñecos; mostrar tolerancia a diversas manifestaciones de juego durante otras actividades como la alimentación, el baño o al despertarlo.

Signos de alarma: no imita; su repertorio de juegos se mantiene limitado por retraso en la integración de nuevas praxias. Prefiere juego estereotipado, no acepta modificaciones ni de juguetes ni de objetivos del juego.

Tres elementos distinguen la condición humana: las capacidades de un pensamiento complejo, el empleo del lenguaje para modular la interacción con los otros y la construcción de valores éticos para regular la conducta. Estos tres componentes se establecen a partir de la infraestructura que se organiza en los primeros años de vida. El potencial para desarrollar el pensamiento dependerá de la genética y la epigenética en un contexto enriquecedor; la capacidad de interactuar en todas las modalidades con el entorno social y la generación de valores éticos se inician con la formación de hábitos elementales en un contexto de reglas dentro de rutinas básicas con flexibilidad y afecto. ${ }^{13}$ No olvidar la importancia que esta etapa tiene como consecuencia: montar la infraestructura del futuro en las mejores condiciones.

En este trabajo, por su brevedad, no es posible plantear todas las estrategias posibles para asesorar cada aspecto señalado. Consideramos que pueden ajustarse por la información a la que se tiene acceso y para cada grupo cultural o social al que se atiende. También es relevante indicar que los funcionamientos seleccionados están estrechamente relacionados, su agrupación es arbitraria ya que todos los elementos se traslapan. No hay movimiento y atención sin motivación, comunicación sin movimiento y emoción sin afecto. La motivación sin visión se dificulta y la inteligencia se retrasa cuando no hay posibilidades de orientarse auditivamente.

Las secuencias de desarrollo aquí presentadas no implican edades estrictas de adquisición. Son un referente y sirven para orientar a los padres respecto del desarrollo de los niños y para apoyarlos en conseguir e impulsar las secuencias esperadas en su hijo. Por otro lado, facilitan la identificación de las características, estilos y hábitos de crianza de cada familia para brindar orientaciones que desarrollen la observación y creatividad al brindarle al niño un ambiente propicio para su formación. Cada pediatra debe recurrir a su capacidad creativa en interacción con la de los padres para adecuar cada sugerencia aquí indicada, ya que los aspectos socioculturales son muy diversos y no se trata de proponer recetas reformuladas sino de modificar lineamientos rígidos similares para todas las situaciones y todas las culturas.

La vigilancia del neurodesarrollo en este contexto implica no sólo su evaluación en el seguimiento sino, básicamente y conforme el planteamiento de Blackman, ${ }^{13}$ intentar remover las barreras al proceso, pensando cómo el desarrollo puede ser facilitado a través de la orientación a la familia en su contexto, lo que casi asegura su efectividad. 


\section{REFERENCIAS}

1. Piaget J. Biología y Conocimiento. México: Siglo XXI; 1985.

2. Rivera González R, Sánchez C, Corral Guille I, Figueroa Olea M, Soler Limón K, Martínez Vázquez I et al. Edad de presentación de los reactivos del Test de Denver Il en Niños de 0 a 4 años de edad del Estado de Morelos. Salud mental. 2013;36(6):459-70.

3. Bustelo E. El recreo de la infancia: Argumentos para otro comienzo. Buenos Aires: Siglo XXI; 2007.

4. Sánchez C, Rivera-González R, Figueroa-Olea M. Promoción del desarrollo infantil temprano: orientaciones y estrategias. México: Editores de Textos Mexicanos; 2009.

5. American Academy of Pediatrics. Identifying infants and young children with developmental disorders in the medical home: An algorithm for developmental surveillance and screening. Pediatrics 2006;118(1):405-20.

6. Rivera-González R, Sánchez C. Vigilancia del desarrollo integral del niño. 1a ed. México, DF: Editores de Textos Mexicanos; 2009.
7. Vericat $A$, Orden $A B$. Herramientas de screening del desarrollo psicomotor en América. Rev Chil Pediatr 2010;81:392-401.

8. Frakenburg WK, Dodds JB, Archer P. Denver II Training Manual. Denver, Colorado: Denver Developmental Materials Inc, 1992.

9. Accardo PJ, Capute AJ. The Capute Scales. Cognitive Adaptive Test/ Clinical Linguistic \& Auditory Milestone Scale (CAT/ CLAMS): Brookes Publishing Company: 2005.

10. Sánchez MC, Benavides $\mathrm{H}$, Mandujano M, Rivera R, Martínez I, Alvarado G. Valoración Neuroconductual del Desarrollo del Lactante (VANEDELA). 3a ed. México: Universidad Autónoma Metropolitana- Xochimilco: 2010.

11. Geva R, Feldman R. A neurobiological model for the effects of early brainstem functioning on the development of behavior and emotion regulation in infants: implications for prenatal and perinatal risk. Journal of Child Psychology and Psychiatry 2008;49(10):1031-41.

12. Narbona J, Chevrie-Muller C. El lenguaje del niño: desarrollo normal, evaluación y trastornos. Barcelona: Masson, 1997.

13. Blackman JA. Early Intervention: A Global Perspective. Infants \& Young Children 2002;15(2):11-9. 